\title{
Autonomías e identidades racionalizadas entre creyentes desde la religiosidad evangélica vivida: el caso limeño
}

\author{
Catalina Romero* \\ Rolando Pérez* \\ Veronique Lecaros*
}

\section{Resumen}

Este artículo aborda el modo como los creyentes evangélicos limeños construyen sus prácticas de espiritualidad vivida en un contexto de movilidad, pluralización y desregulación del campo religioso peruano. Nos interesa observar el modo como los creyentes vinculados al protestantismo urbano limeño, ciudad tradicionalmente marcada por la institucionalidad católica y una religiosidad evangélica circunscrita al espacio del templo, desarrollan nuevas vivencias autónomas de la fe e interactúan con otros espacios religiosos y seculares. En ese sentido, nos interesa analizar los nuevos espacios culturales y territorios religiosos desde los cuales el creyente evangélico vive su espiritualidad cotidiana, construye nuevos sentidos y descubre nuevas formas de vivir y de expresar su identidad religiosa, así como su adscripción a la institución religiosa. Este caso nos permite analizar el modo como el contexto de la pluralización del campo religioso y el escenario de la secularización construyen nuevos perfiles para el creyente evangélico que empieza a abrazar determinadas formas de autonomía.

Palabras clave: espiritualidad evangélica vivida, protestantismo urbano, autonomía religiosa, pluralismo religioso.

*Pontificia Universidad Católica del Peru, Lima, Peru. 


\section{Autonomies and rationalized identities in the lived evangelical religiosity of believers: the Lima's case}

\section{Abstract}

This article addresses the way in which evangelical believers of Lima, in Peru, build their practices of lived spirituality in a context of mobility, pluralization and deregulation of the Peruvian religious field. We are interested in observing the way in which believers linked to Lima urban Protestantism, a city traditionally marked by Catholic institutions and by an evangelical religiosity circumscribed to the space of the churches, develop new autonomous experiences of the faith and interact with other religious and secular spaces. In that sense, we are interested in analyzing the new cultural spaces and religious territories from which the evangelical believer lives his/her daily spirituality, builds new senses and discovers new ways of living and expressing his/her religious identity and ascription to the religious institution. This case allows us to analyze the way in which the context of pluralization of the religious field and the scenario of secularization build new profiles for the evangelical believer, who begins to embrace certain forms of autonomy.

Keywords: lived evangelical spirituality, urban protestantism, religious autonomy, religious pluralism.

\section{El campo evangélico peruano}

$\mathbf{E}$

n las décadas recientes, el crecimiento de las iglesias evangélicas y pentecostales, así como de las neo pentecostales ha hecho más visible su presencia en diferentes espacios sociales y políticos, y en diferentes lugares del territorio nacional y continental. La diversidad de creencias y de prácticas religiosas también ha aumentado, tanto al interior de la Iglesia católica como de las iglesias y denominaciones evangélicas.

El Perú, como el resto de los países de América Latina está transitando de un contexto marcado por la predominancia del catolicismo a ser un país de pluralidad religiosa con mayoría cristiana. Esta situación empezó a cambiar desde mediados del siglo XX, aunque la presencia de otras iglesias cristianas estaba ya presente en el continente y en el Perú desde inicios del siglo XIX. 
Es importante mencionar que la llegada de los primeros protestantes al Perú en el siglo XIX respondió a razones no solo religiosas, sino también económicas y políticas. De este modo, es posible observar las huellas de sus precursores más allá del ámbito estrictamente eclesiástico. Los protestantes llegaron al Perú durante el siglo XIX e inicios del XX, traído por los inmigrantes anglosajones (luteranos y anglicanos), luego abriendo sus puertas a los peruanos (Fonseca, 2018). Recogiendo el trabajo de autores clásicos que analizan la presencia protestante en el Perú (Marzal, 2000; Míguez-Bonino, 1995; Escobar, 2002), Fonseca plantea cuatro tendencias. Primero, el protestantismo histórico, constituido por denominaciones cuyos orígenes históricos se remontan a la Reforma protestante del siglo XVI o el avivamiento metodista del XVIII. Segundo, el protestantismo evangélico, que se estableció en el Perú en las primeras décadas del siglo XX y tiene estructura eclesial similar a la del protestantismo histórico, pero con una teología conservadora y/o fundamentalista, puesto que basada en la interpretación literal de la Biblia y en una marcada ortodoxia teológica. Tercero, el pentecostalismo clásico, nacido como movimiento de renovación religiosa del protestantismo evangélico mundial al comienzo del siglo XX, que llega al Perú en 1919, al principio estableciendo comunidades casi exclusivamente entre los sectores más pobres del país como las periferias urbanas y el mundo rural. Aunque su teología y su hermenéutica sean similares a la de los protestantes evangélicos, el pentecostalismo clásico tiene una religiosidad distinta, caracterizada por una piedad entusiástica en la que el cotidiano del creyente es permeado por el sobrenatural. Cuarto, el neo-pentecostalismo o carismatismo, nacido en la década de 1970 dentro de las denominaciones históricas, incluyendo a la Iglesia Católica, que emerge en el Perú en fines de la década de 1980, sea en el seno de denominaciones evangélicas o de manera independiente (Fonseca 2018).

En la actualidad, como en la mayoría de los países latinoamericanos, la diversidad de ritualidades católicas y evangélicas se extiende más allá de los tradicionales recintos eclesiásticos, con la creación de estrategias de presencia e interacción pública (Levine, 2009). En ese mismo sentido, el pluralismo religioso da cuenta no solo de la emergencia de nuevos rostros, sino también de la interacción entre personas con diferentes creencias unidas por afinidades culturales, locales y familiares, y de la construcción de 
nuevas prácticas de religiosidad y espiritualidad que los creyentes generan en la vida cotidiana y socializan en el espacio público.

En este contexto, el campo evangélico ${ }^{1}$ peruano es cada vez más plural y diverso en su configuración, así como en sus formas y lógicas de acción e interacción dentro y fuera de su territorio eclesial. En ese sentido, podemos observar cambios sustanciales "en su composición social, en el porcentaje de sus adherentes y en sus expresiones litúrgicas" (PérezGuadalupe, 2017, p. 21).

Si bien el crecimiento demográfico de los evangélicos es una variable significativa, es importante observar el modo como los agentes de este sector religioso han empezado a construir una actoría pública de mayor incidencia. Esto tiene repercusiones en la propia autocomprensión identitaria de los fieles ligados a las iglesias evangélicas. En ese sentido,

los líderes evangélicos no solo son conscientes de que representan a la comunidad religiosa más dinámica y expansiva del país, sino que también tienen claro que este hecho les ha servido para construir entre sus fieles, en particular entre los más conservadores, una narrativa en torno a su lugar en la sociedad peruana. Dicha narrativa plantea la idea de que, aunque son un segmento significativo de la sociedad peruana, no están suficientemente reconocidos ni representados en ella (Fonseca, 2018, p. 40).

La batalla que libran determinados sectores evangélicos por salir de la marginalidad y acceder al espacio público no es nueva. Como afirma Pérez (2016, p. 213),

Lo relevante es el modo en que las estrategias de apropiación, empoderamiento e incidencia en lo público están generando un proceso de re-significación tanto a nivel de los discursos y de los roles que especialmente los sectores religiosos emergentes empiezan a jugar, como a nivel de las estrategias de incidencia en espacios sociales y políticos. Esto incluye nuevas formas de construcción del poder no solo religioso, sino también político, que trae consigo las nuevas estrategias de relacionamiento con las estructuras de poder y actores que se mueven en el ámbito secular.

${ }^{1}$ Los resultados del último Censo de población y vivienda del Perú (INEI,2018) colocan a los evangélicos en el 14,1\%. Los demás datos son los siguiente: el 76\% son católicos, el $4,8 \%$ tiene otro credo (lo que incluye a adventistas, testigos de Jehová, mormones, israelitas, budistas, musulmanes, entre otros) y en el 5,1\% se ubican los ciudadanos sin religión. 
En el caso de los sectores evangélicos, es posible observar el surgimiento de actores que se conectan de manera más fluida con el quehacer público, involucrándose en el abordaje de los problemas sociales y en los debates mediáticos en el espacio secular. Estratégicamente, se puede observar que muchos de ellos están desarrollando diversas tácticas y estrategias para construir relaciones e interacciones cercanas con agentes políticos y sociales influyentes.

A este respecto, es importante señalar que los estudios contemporáneos sobre el protestantismo no nos permiten observar la complejidad del campo evangélico contemporáneo, especialmente con relación al modo como se construyen las nuevas identidades, interacciones y pertenencias. Por ello, una mirada desde los discursos y las prácticas cotidianas de los creyentes nos ayuda a conocer las repercusiones e incidencias de la experiencia religiosa en la vida cotidiana. A este nivel, es interesante "bucear en los aspectos de la religiosidad que tensionan las dicotomías público/privado, material/ espiritual, razón/emoción, rescatando aspectos que las personas consideran importantes en sus vidas" (Rabbia et al., 2019, p.17).

\section{Sobre los sujetos de nuestro estudio}

El análisis que realizamos para este artículo tiene como fuente principal los resultados del estudio que 11 investigadores de cuatro universidades (Boston College, Pontificia Universidad Católica del Perú, Universidad Católica de Córdoba y Universidad Católica del Uruguay) desarrollamos entre 2015 y 2016. El estudio tuvo el propósito de explorar el sentido de las prácticas religiosas desde la experiencia cotidiana de los sudamericanos. La investigación recoge la propuesta teórica y metodológica de la socióloga Nancy Ammerman (2014), quien estudió las implicancias de la religiosidad vivida en personas que residen en las ciudades norteamericanas de Boston y Atlanta.

El estudio, que se aplicó en las ciudades de Córdoba (Argentina), Montevideo (Uruguay) y Lima (Perú), se concentró en el análisis de

las narrativas de espiritualidad, es decir, las historias que las personas cuentan sobre sus prácticas religiosas, espirituales y no religiosas vinculadas a su concepción particular de los trascendente. Igualmente, recogimos las narrativas autobiográficas de las personas que participaron del estudio, con énfasis en las continuidades y rupturas de sus experiencias religiosas y espirituales (Rabbia et al., 2019, p. 18). 
En el caso de la indagación sobre el caso de los creyentes evangélicos en Lima, recogimos las historias de creyentes de comunidades o congregaciones evangélicas ubicadas en los estratos alto/medio y bajo. La delimitación, cuya muestra fue intencional, contempló una variedad de edades, género y situaciones vitales (personas solteras y casadas, con hijos y sin hijos, nativos y migrante). Asimismo, incluimos a miembros de la variedad denominacional del campo evangélico limeño. En ese sentido, los entrevistados pertenecen a las siguientes iglesias: del protestantismo histórico - Iglesia Metodista del Perú, Iglesia Evangélica Luterana; del protestantismo evangélico - Iglesia del Nazareno, Iglesia Evangélica Peruana, Alianza Cristiana y Misionera; del protestantismo pentecostal clásico - Asamblea de Dios del Peru, Iglesia de Dios del Perú; del protestantismo neo-pentecostal - Iglesia Agua Viva, Iglesia Bíblica Emmanuel, Movimiento Misionero Mundial.

\section{Entre la autonomía y la adscripción a la institución religiosa}

Los evangélicos latinoamericanos, en general, y peruanos, en particular, han construido su identidad religiosa sobre la base, entre otras cosas, de una marcada fidelización a las normas y las practicas rituales normadas por la institución eclesiástica, de la que dan cuenta las encuestas sobre religión en América Latina, como lo confirma aquella realizada por el Pew Research Center (2014). Para los evangélicos, la religión es más importante que para los católicos (90 a 70\%). Los evangélicos afirman en mayor proporción que los católicos su asistencia al culto semanal (60 a 30\%), su práctica de oración cotidiana (75 a 46\%), la lectura de la Biblia (55 a 15\%), el involucramiento en los quehaceres eclesiásticos (32 a 9\%), el compromiso con el diezmo (66 a $12 \%$ ) y la práctica del ayuno (57 a 24\%). Ciertamente, a parte de la asistencia a la misa dominical, la jerarquía católica no considera obligatorias las demás prácticas, pero, en todo caso, la encuesta revela que la mayoría de los evangélicos mantiene, en su quehacer cotidiano, una disciplina religiosa intensa. Probablemente esto se enfatiza entre los recién convertidos que están creciendo en todo el continente, según la encuesta del Pew Research Center (2014). "Solo uno de cada diez latinoamericanos (9\%) fueron criados en iglesias protestantes, pero casi uno de cada cinco (19\%) ahora se describe como protestante" (Pew Research Center, 2014, p. 3). 
En algunos países, los creyentes tienden a sobrevalorar sus prácticas religiosas y ese es el caso del Perú (Cleary, 2004; Casanova, 2009; Lecaros, 2019). Esta sobrevaloración representa en sí un indicio de la importancia de la religión y de sus normas de parte de la feligresía.

¿Podríamos decir, entonces, que existe poca autonomía de los evangélicos con relación a sus iglesias? ¿Deberíamos buscarla en estos 40\% que no siguen rigurosamente las normas? Los datos que arroja el estudio del Pew Research Center no nos permiten encontrar respuesta a este tipo de preguntas. Precisamente, el estudio que realizamos sobre el modo como los creyentes y no creyentes viven su fe o construyen su relación con la trascendencia en la vida cotidiana busca responder a inquietudes de esta naturaleza.

Danièle Hervieu-Léger (2004), estudiando la evolución religiosa en Francia, distingue, aparte de los feligreses tradicionales cada vez menos numerosos, dos tipos de creyentes: los convertidos y los peregrinos ${ }^{2}$. Los convertidos, una minoría, suelen cumplir sigilosamente con las normas de su denominación mientras que los peregrinos mantienen un alejamiento de su comunidad y se acercan a ella esporádicamente cuando ellos mismos sienten la necesidad. Hervieu-Léger caracteriza esta situación como un "bricolaje", al antojo y parecer del creyente. En esta misma línea, desde la experiencia latinoamericana, Cristian Parker (2009) y Fortunato Mallimacci (2015), entre otros, refieren a la emergencia del que se dice ser "católico a mi manera".

Retomando la distinción de Hervieu-Léger (2004), los evangélicos podrían ubicarse en la categoría de los convertidos. Por una parte, 66\% de los evangélicos, según la encuesta del Pew Research Center (2014), provienen de canteras católicas y entonces han experimentado el proceso de la conversión o el cambio de denominación. Por otra parte, la lógica evangélica del "born again" (volver a nacer) implica que un individuo, por más que haya nacido en la tradición evangélica, debe asumir personalmente su adscripción a la fe protestante y plegarse, por voluntad propia, a las

${ }^{2}$ La conversión puede ocurrir en el seno mismo de su tradición religiosa. Los re-iniciantes suelen ser personas alejadas de la religión de sus familias que deciden en algún momento retomar (o tomar) la práctica de los ritos, de la oración o el contacto con una comunidad de fe. Lo que otrora era herencia, se vuelve compromiso personal (Lecaros, 2017). 
normas de su iglesia. La encuesta del Pew refleja esta situación, en el sentido de que el evangélico se esmera o tiene por ideal el cumplimiento de las normas de su Iglesia. En esta perspectiva, entonces, hablar de "autonomía evangélica" suena a oxímoron.

Sin embargo, la conversión no es una situación estática. Es un proceso dinámico (Hervieu-Léger, 2004). Precisamente, los testimonios que presentaremos indican que el itinerario que experimentan los creyentes evangélicos da cuenta de variadas formas de autonomía, que implican diversas formas de pertenecer a la iglesia y relacionarse con la comunidad religiosa. En ese sentido, nos proponemos analizar algunos aspectos de estas modalidades de autonomía construidas desde la lógica de los creyentes evangélicos.

Previamente, es importante mencionar que no deberíamos identificar la autonomía como un rechazo - temporal o no - de la iglesia y sus reglas. En este caso se trata de una suerte de transgresión: las personas siguen teniendo como norma las reglas, aunque no las sigan, como es el caso de la experiencia de algunos de nuestros entrevistados. Muchos de ellos, a pesar de haberse alejado temporalmente de su iglesia, han seguido valorando las reglas y a posteriori consideran que nunca debieron romper con la disciplina. Por ejemplo, Luciana (42 años, clase alta, miembro de la Iglesia neo-pentecostal "Agua Viva", diseñadora de moda) y Katy (23 años, clase media baja, miembro de la Iglesia pentecostal Asambleas de Dios) han transitado por este peregrinaje que implicó el alejamiento por un largo tiempo de su iglesia. Luciana se apartó de la congregación por la presión de su novio católico, pues se sentía culpable por tener relaciones sexuales antes del matrimonio. Finalmente, luego de romper con dicha relación, retornó a su misma iglesia. Katy, hija de pastor, tuvo su momento de "rebeldía" y por un año dejó la familia y la congregación. Luego de un tiempo retornó a su iglesia.

Por otro lado, observamos aquí una suerte de flexibilización de la disciplina evangélica, que es una característica de los movimientos que corresponden a lo que Paul Freston ha llamado la segunda y tercera ola pentecostal (Freston, 2016; Oualalou, 2018; Fonseca, 2018). En la primera ola podemos ubicar a las iglesias caracterizadas por comportamientos muy 
rígidos respecto al de determinadas costumbres en la vida cotidiana, lo cual implicaba, en muchos casos, un alejamiento de la familia y de los amigos.

No podemos identificar la autonomía del creyente con este fenómeno. Muchas de estas iglesias flexibilizan sus requerimientos bajo la presión de su feligresía.

\section{La racionalidad pentecostal como potenciadora de autonomía}

Es importante mencionar que el protestantismo, al ofrecer a todos los creyentes la posibilidad del acceso directo y personal a la Biblia - autoridad máxima para esta corriente del cristianismo -, ha representado una forma de liberación del individuo. Según la fórmula provocadora del escritor francés del siglo XVII, Boileau, "todo protestante es un Papa con una Biblia en la mano" (Picon; Gagnebin, 2005, p. 5). Como lo sostienen Picon y Gagnebin, el protestantismo en sí representa una posibilidad de autonomía porque abre al individuo la posibilidad de contrastar la enseñanza de la iglesia con la Biblia.

En el seno del protestantismo, el pentecostalismo representa una mayor potencialidad de autonomía por la relación directa del individuo con la divinidad. Entre los textos bíblicos de referencia que confirman la validez y la "legitimidad de la experiencia religiosa" (Miller, 2013, p. 8), cabe desatacar Juan 3, 8 ("El viento sopla de donde quiere, y oye su sonido; mas ni sabes de dónde viene, ni a dónde va; así es todo aquel que es nacido del Espíritu") y Hechos 4, 19 ("Juzgad si es justo delante de Dios obedecer a vosotros antes que a Dios" $)^{3}$.

Potencialmente, entonces, existe una forma de autonomía en relación a su institución que tiene que ver con el modo como cada creyente asume o interpreta el mandato o la autoridad divina (el modo como el creyente asume la indicación de Dios en una situación determinada). Como lo plantea Miller, "la experiencia directa divina no necesariamente se explica exclusivamente por la clase sacerdotal" (Miller, 2013, p. 8).

\footnotetext{
${ }^{3}$ Textos citados a partir de la traducción de Reina-Valera comúnmente adoptada por los evangélicos.
} 
En el relato de Lili (28 años, trabajadora independiente, miembro de la Iglesia neo-pentecostal Emmanuel), se puede notar recurrentemente, como una suerte de leitmotiv, la referencia a la palabra obedecer. Sin embargo, no se refiere a la autoridad impuesta por alguna instancia o a la obediencia cerrada a algunas consignas de los líderes. Más bien, ella construye su valoración de la autoridad espiritual a partir de una contrastación reflexiva entre el discurso de los líderes y su propia interpretación del texto bíblico. Ella explica su actuación de esta manera: "yo me baso conforme a las enseñanzas que aprendí de los pastores, de los líderes y conforme a la Biblia. Cuando ellos me dicen una palabra, tengo que ver lo que dice la Biblia". Por ejemplo, en relación con la costumbre femenina de su congregación respecto al no uso de la minifalda, ella refiere que "esto lo hacemos conforme a la palabra de Dios. Dios va tratando tu corazón, tú también tienes que entrar en consciencia" que por la minifalda te "expones". Lili añade lo siguiente: "El límite que las mujeres debemos tener debe ser conforme a la palabra de Dios, no por lo que el pastor lo diga, un límite porque tú entiendes lo que dice la palabra de Dios 'vestirse con decoro'. Así dice la Biblia".

Si bien, existe la posibilidad de una apertura hacia la autonomía individual en tanto que se asume que la conexión con la trascendencia no requiere de intermediarios eclesiales, como lo notó Christian Lalive d'Epinay (1968). En esa misma línea, André Droogers (2014, p. 198) subraya que

la creencia en el Espíritu Santo rehabilita al creyente individual y, sin embargo, el liderazgo de los pastores puede volverse más fuerte que la autoridad de la experiencia individual del Espíritu. [...] La experiencia es primera y primordial $y$, sin embargo, una doctrina estricta puede prevalecer.

Precisamente, el perfil de un sector de creyentes evangélicos contemporáneos, que asume la autoridad y las normas de la iglesia con menos obediencia acrítica que antes, nos muestra un escenario nuevo, caracterizado por una cierta tensión entre la cultura de la imposición de la doctrina y la experiencia de un creyente que empieza a experimentar o anhelar determinadas prácticas autónomas. En este sentido, es posible 
notar espacios o intersticios potenciales desde lo que se pueden construir prácticas de autonomía entre los creyentes.

José Sánchez, en su estudio de la iglesia pentecostal Ríos de Agua Viva, observa ciertos cambios en el modo como los creyentes perciben y asumen la autoridad: "[s]i en el viejo modelo pentecostal clásico la característica predominante era la verticalidad jerárquica de su organización y sistema de autoridad y liderazgo, en el nuevo modelo la característica central será su fuerte tendencia democrática" (Sánchez, 2016, p. 227). En este caso, no se trata de una flexibilización de las reglas sino de nuevas estrategias pastorales que no invalidan las iniciativas personales que, en varios fieles, se evidencian como formas de autonomía que ellos mismos asumen, aunque no empleen la palabra, dado que la autonomía no representa necesariamente un valor deseable en algunas iglesias.

Con respecto a los casos estudiados, encontramos dos tendencias con relación a la autonomía. Uno de ellas tiene que ver con el tipo de creyente que al convertirse mantiene su criterio personal y su percepción a veces contraria a la posición de su iglesia en determinados asuntos teológicos o doctrinales.

Henry Gooren (2010), en sus estudios sobre conversión en América Latina, observa que un recorrido dinámico en la historia de muchos creyentes en su proceso de conversión (Lecaros, 2017), en el cual el individuo pasa por varias etapas que representan una profundización de su compromiso religioso y de su amoldamiento en la institución. Sin embargo, es importante mencionar que algunos nunca llegan a completar el recorrido y se quedan como afiliados sin asimilar necesariamente todos los aspectos de la doctrina o las normas de la iglesia.

Aldo (50 años, clase media alta) podría ser considerado como un ejemplo de este tipo de conversión. En el momento de la entrevista, Aldo tenía tres años congregando a la Iglesia Emmanuel. Después de experimentar unos años problemáticos, incluyendo un proceso crítico de depresión, decide adscribirse a esta congregación, gracias a la invitación de su esposa. Si bien reconoce las experiencias positivas vividas desde que se incorporó en esta congregación, Aldo marca distancias con algunas de las creencias de la referida iglesia - "tengo una relación muy particular... o sea no acepto muchas cosas". Por ejemplo, precisa que, por su condición 
de ingeniero, tiene discrepancias con la imagen de Dios que los líderes construyen. "Por más que quiera, no puedo creer en un Dios castigador, porque si castiga deja de ser Dios".

En la segunda tendencia, ubicamos a aquellos creyentes que, luego de un tiempo de adoptar y cumplir con las normas de la iglesia, en algún momento de su peregrinaje deciden afirmar su autonomía.

Este es el caso de Andrés (20 años), quien ahora tiene resistencias para aceptar el mandato de su iglesia con relación a la castidad. Su itinerario religioso da cuenta de que su caso correspondería al de la transición del creyente "fanático" y "pegado a la letra" al feligrés más flexible y abierto. "Antes creía que todo era Dios, que Dios lo haría todo por mí. [...] Entonces, yo me alejaba un poquito de las otras cosas de mi vida [...]. Pero ya luego pasaron los años y me di cuenta de que, en realidad, Dios, lo único que puede hacer para ti es darte la vida para que tú hagas las cosas".

Moisés (40 años, dentista, clase media, provinciano), un creyente fervoroso, mantiene las prácticas tradicionales de la espiritualidad evangélica, como las oraciones diarias y las lecturas cotidianas de la Biblia. Pero, manifiesta que en el proceso de su vida religiosa ha ido adoptando formas menos rígidas de vivir su fe. "Yo busco tener cada día una relación personal con el Señor [...] cuando empecé, hubo gente que me guió, pero hoy en día, yo camino ya solo con el Señor". Si bien él continúa siendo un creyente evangélico fiel a las normas que exigen las iglesias tradicionales - como no consumir alcohol, escuchar "música cristiana", no asistir a las fiestas bailables etc. -, ha decidido asistir al culto solamente una vez al mes. Adicionalmente, ha desarrollado una intensa labor social. Usa su profesión de odontólogo para involucrarse en la obra social, atendiendo gratuitamente a personas que viven en los barrios marginales.

Blanco, quien, aunque sigue reconociéndose como un creyente evangélico, no mantiene relación con ninguna iglesia. Sin embargo, sigue "predicando la Palabra" y "orando con sus compañeros de trabajo". Blanco ha llegado al punto de la desafiliación, una situación mucho más radical que Moisés, quien sigue manteniendo un cierto vínculo con su iglesia, aunque no perciba la necesidad de establecer compromisos formales con los quehaceres propios de la vida congregacional evangélica. 
La diferencia entre el caso de Aldo y de aquellos que han llegado a la autonomía después de un largo recorrido en la iglesia, se manifiesta en el tipo de lenguaje que utilizan al referirse a los asuntos espirituales o eclesiásticos y en el modo como conciben o analizan el papel de los lideres o la propia misión de la iglesia. Por ejemplo, Moisés y Blanco siguen usando un determinado vocabulario evangélico para narrar e interpretar sus historias, como "congregar" (ir al culto, pertenecer a una iglesia) y "predicar la palabra" (una forma de asumir la tarea de la evangelización desde la fe evangélica).

\section{La pluralización religiosa exógena como potenciadora de autonomía}

Entendemos por pluralización religiosa al fenómeno que viene ocurriendo en América Latina desde mediados del siglo XX, con diferencias de intensidad según el país - proceso que se ha acelerado en el cambio de siglo y constituye hoy una nueva realidad en lo que a la religión se refiere. La presencia de una diversidad de religiones, en su mayoría cristianas, con un fuerte peso del catolicismo - que todavía supera el 50\% de la población creyente en la mayoría del continente - replantea el lugar de la religión en la sociedad, respecto al individuo y a la política, y se visibiliza en la vida cotidiana.

Peter Berger (2014), en su última obra, considera la 'pluralización' como un nuevo paradigma para estudiar el campo religioso, cuya significación e inmenso potencial todavía no ha sido analizado. Cabe recalcar que, aunque se trate de un fenómeno global, con algunas excepciones, presenta especificidades locales. En este horizonte cristiano, al creyente urbano peruano se le abren múltiples opciones que nuestros entrevistados han mencionado al relatar su experiencia de conocer otras religiones por tener familiares o amigos de otras iglesias. Muchos de los que han transitado de la Iglesia católica a iglesias evangélicas o pentecostales mencionan haber sido incorporados a alguna congregación de esa tradición confesional gracias a la invitación de una persona de su entorno.

Berger afirma que la pluralización transforma al individuo en "agente" (Berger, 2014). En muchos de los casos de creyentes evangélicos, se 
observa que la decisión de convertirse y adscribirse a la fe evangélica vino precedida de un proceso de contacto y exploración con varias comunidades de creyentes, así como de una serie de experiencias personales con lo trascendente.

Mario (clase media, 40 años) adquiere su formación en la fe evangélica en la provincia de Chimbote, en el seno de una familia pentecostal, de la cual mantiene la tradición de la oración personal diaria. Sin embargo, al llegar a Lima, cambian sus perspectivas y se muda a otra iglesia. Luego de congregar por muchos años en una iglesia de trasfondo pentecostal, decide pertenecer a una iglesia vinculada al luteranismo histórico. Así lo expresa: "producto de mis estudios, voy adquiriendo nuevos conocimientos, nuevas perspectivas y sentí que la iglesia donde había sido formado, no encajaba conmigo, así que me identifiqué con otra iglesia que sí me parece que va un poco con las cosas que yo creo ahora".

Lili refiere que le pide a Dios que "le dé una dirección a qué Iglesia ir". Luciana pasa varios años en una Iglesia, sin estar totalmente convencida. Unos años después decide congregarse en la iglesia neo-pentecostal Agua Viva.

Moisés relata que, cuando tenía 23 años, al afrontar serios problemas en su vida conyugal, es llevado por un amigo a un culto evangélico: "él me invitó, pero yo sé que fue Dios [...]. Dios me hablaba, me hablaba, me hablaba...". A pesar de esta intensa experiencia, Moisés no se queda en esta iglesia, a la que ahora califica como tradicional y conservadora. Luego, decide asistir y congregarse de manera permanente en una de las iglesias de la Alianza Cristiana y Misionera.

Excepto en el caso de Mario, quien interpreta su incorporación a su nueva iglesia como una elección individual, producto de su propia reflexión en relación con Dios y la propia iglesia, para los demás pentecostales, el cambio ocurre como consecuencia de - según ellos - una orientación o dirección divina. En la dinámica de un sector del pentecostalismo, a pesar de sus diversas y jerarquizadas fuentes de autoridad, se puede observar una particular forma de autonomía con relación a los pastores y a la institución eclesiástica. Sin embargo, el individuo no lo expresa de esta manera.

Un aspecto común, que es posible observar en el relato de los entrevistados, tiene que ver con el hecho de que la interacción con otros 
espacios y personas - especialmente con aquellos en los que su fe y su manera de comprender la espiritualidad ha sido construida desde otros referentes - genera un perfil de creyente que se mueve en el marco de un tipo de "autonomía interpretativa" (Dillon, 2017).

Aun cuando este proceso interpretativo, que tiene un componente crítico sobre las normas y prácticas ortodoxas de la iglesia, construye el perfil de "creyentes evangélicos a mi manera", estos fieles no han optado por la desafiliación confesional. Se mueven de una iglesia a otra, con autonomía, pero siguen afirmando su identidad evangélica con variaciones.

\section{Las reapropiaciones territoriales del creyente evangélico urbano}

Como mencionamos antes, tradicionalmente el campo evangélico se ha caracterizado por la presencia de creyentes que marcaron su proceso de fidelización con la fe evangélica a partir de la aceptación de las reglas y la obediencia a la autoridad religiosa. Sin embargo, en los años recientes, observamos que los sentidos de pertenencia a la comunidad religiosa se construyen desde formas más flexibles con respecto a las percepciones y prácticas de la vivencia de la fe.

Nuestro estudio da cuenta de que determinados espacios concebidos en el pasado como "lugares mundanos" - como el ámbito laboral, la familia "no creyente", los espacios e instancias de interacción con los amigos constituyen hoy lugares por los que los creyentes evangélicos transitan o interactúan con más frecuencia que antes. Las reapropiaciones de estos espacios seculares generan interacciones más fluidas entre lo sagrado y lo profano, e incluso resignificaciones de aquellas prácticas ecuménicas no aceptadas o censuradas en los círculos evangélicos en el pasado.

Este es el caso de Milagros (40 años, casada, de clase media). Ella creció en el seno de una familia evangélica, y desde joven estuvo muy involucrada en los quehaceres de la iglesia. Incluso concluyó los estudios teológicos en el seminario de su denominación. En aquella época, Milagros estaba entusiasmada por dedicarse a tiempo completo a, lo que ella llama, la vida ministerial. Sin embargo, luego de incorporarse laboralmente a entidades seculares para ejercer su carrera profesional de comunicadora social, hizo un 
giro significativo no solo respecto a la compresión de su fe, sino también con relación a su concepción sobre el sentido del involucramiento en la comunidad evangélica de que era parte.

Ahora ya no pienso lo mismo que pensaba cuando me convertí. En ese tiempo no podía hacer las cosas de manera distinta a lo que los líderes pensaban. Yo empecé a reflexionar en todo esto, y pensé que tengo que cambiar. Y pienso que no se trata de dejar a Dios o a la iglesia, sino estar un poco más abiertos, porque creo que Dios no nos llama para estar dentro, sino afuera (Milagros).

El de Milagros es un típico caso de una creyente evangélica que transita de la situación de alguien que construyó su espiritualidad sobre la base de la obediencia casi acrítica a la autoridad eclesiástica a la de una creyente que construye su propia interpretación y definición de una manera de pertenecer a la institución religiosa.

Muchas de las historias e itinerarios de los creyentes evangélicos que entrevistamos revelan que hoy tienden a transitar entre diversas pertenencias tanto dentro como fuera del campo evangélico. Es frecuente observar la migración de miembros de iglesias protestantes tradicionales a las emergentes comunidades evangélicas y viceversa. En este sector la tendencia parece ser la de tomar distancia de las fidelidades religiosas exclusivistas y el sometimiento acrítico a la autoridad eclesiástica.

Este tipo de creyentes evangélicos que viven su experiencia de fe marcada por la movilidad hacia ámbitos o espacios que están fuera del marco de la institución religiosa han encontrado o construido una suerte de comunidades de frontera, que les permite transitar por otros pasillos intra o extra religiosos sin desconectarse completamente de su territorio congregacional tradicional. Es interesante notar que, cuando Milagros decide salir del círculo de su iglesia, toma contacto con otros creyentes evangélicos que estaban involucrados en proyectos sociales desde una perspectiva de fe diferente a la de su iglesia.

El caso de Isaac (25 años, estudiante universitario, de clase media) es muy parecido al de Milagros. Cuando él ingresó a la universidad, 
se vinculó con un grupo de estudiantes evangélicos, conocido como la "comunidad bíblica universitaria" (CBU) ${ }^{4}$.

Allí yo encontré un grupo un poco más abierto que en mi iglesia. Mi iglesia es un poco conservadora en algunos aspectos. En la CBU se comparten muchas cosas diferentes. Allí se puede hablar no solamente de la vida cristiana, sino también de la vida académica. Allí es como si puedo ser yo mismo, y sé que no va a haber tanto prejuicio por las cosas que puedo pensar y hacer. Por ejemplo, yo participo en un grupo de danza en la universidad, y en la CBU entienden lo que hago, pero en mi iglesia lo pueden tomar como baile, y el baile como que está estigmatizado en mi iglesia.

Otro sector de creyentes ha encontrado al interior de la propia iglesia "círculos de hermanos" que les permiten seguir participando o estar vinculados a su comunidad evangélica, aun cuando estén en desacuerdo con las formas de ejercicio del poder, las posturas oficiales de la iglesia sobre ciertos temas e incluso con las "prédicas" pastorales del domingo. Varios de los entrevistados refieren que han decidido continuar en ese círculo religioso porque han encontrado amistades entrañables y "hermanos o hermanas" que se han constituido en su nueva familia.

Juanita se congrega en la iglesia Alianza Cristiana y Misionera desde hace más de 20 años. Ella es parte del ministerio que se dedica al cuidado de los bebés durante el servicio dominical. Ella refiere que el momento que más disfruta de este servicio es el tiempo que comparte con "las hermanas" fuera de la iglesia.

Nosotras hemos formado un lindo grupo con las hermanas del ministerio de apoyo a la niñez. Claro, cualquier problema, cualquier cosa que he tenido, con esa confianza, les he contado y, bueno, ellos me han ayudado bastante también con sus palabras. Como yo le digo a mis hijos: "mis hermanos, los de la iglesia, son mi familia". Tengo confianza para contarles mis cosas porque sé que ahí no hay hipocresía.... Compartimos el almuerzo después del culto, pasamos la tarde juntas, y luego me voy más tranquila a mi casa (Juanita).

${ }^{4}$ La Comunidad Bíblica Universitaria es parte del movimiento universitario evangélico en Perú, denominado Asociación de Grupos Evangélicos Universitarios del Perú (AGEUP). Esta es una agrupación integrada por jóvenes universitarios de diversas iglesias evangélicas. Una de las características de esta asociación es que propicia un dialogo entre la realidad sociopolítica y la fe evangélica. 
Muchos de estos creyentes evangélicos dan cuenta de que en su peregrinaje por estas nuevas búsquedas de espacios de fe más abiertos han encontrado otras redes que se mueven en la frontera entre la sociedad eclesial y los pasillos de la sociedad no religiosa. En ese sentido, es interesante notar la aparición de colectivos y redes interdenominacionales conectadas con el mundo secular, que se convierten en comunidades receptoras de los creyentes evangélicos que se encuentran en una situación de nuevas búsquedas. Este es el caso de muchos jóvenes que empiezan a afirmar su fidelidad evangélica desde esos espacios. Las redes sociales (provistas por la comunicación tecnológica) constituyen un soporte nuevo en este proceso de interacción con los nuevos territorios.

Estos círculos construyen un sentido más heterodoxo de la creencia y alientan una articulación más fluida y más comunicante entre la fe evangélica y las problemáticas seculares, entre la pastoral evangélica y los nuevos simpatizantes religiosos.

Este es el caso de Edgardo, quien, luego de muchos años de distanciamiento de su iglesia originaria, una congregación nazarena, ha decidido pasar a una comunidad evangélica que tiene sede en una ciudad de São Paulo, Brasil. "Uno de mis amigos me dijo que había encontrado una Iglesia como la que nosotros pensábamos en los 80. Luego me contacté con ellos. En ese momento les dije que por ahora no quiero saber nada de Iglesia. Pero, ahora estoy con ellos. Nos vemos cada año, y creo que es mi comunidad." Edgardo ha decidido hacerse miembro de esta iglesia brasileña. Todos los domingos participa del servicio religioso a través de la internet. Escucha los sermones y algunos pasajes de los servicios dominicales vía You Tube.

Todo esto nos Ileva a pensar que estamos frente a un tipo de creyente evangélico desterritorializado y afirmado en la construcción de nuevos espacios y prácticas de fe que rompen con la lógica del proselitismo entusiasta y el conversionismo compulsivo que marcó, por muchos años, la identidad de un vasto sector de creyentes que se convirtieron al protestantismo evangélico.

Por ejemplo, Milagros, siendo evangélica, tiene a sus hijos estudiando en un colegio parroquial católico y no se preocupa en convertir a los padres de los amigos de sus hijos para cumplir con su misión. Pero sí comparte su 
fe con ellos. "Lo que quiero es que ellos [sus hijos] conozcan más de Dios y si allí pueden encontrarlo, mi esposo y yo estamos tranquilos", refiere. Ana, una creyente de una congregación evangélica en una zona pobre de la provincia limeña del Callao, menciona que en los últimos años participa con más frecuencia en actividades sociales fuera de la iglesia, y que lo hace porque piensa que su "llamado a servir a Dios" está entre los no creyentes. Edgard se autodenomina un practicante de la fe más que un creyente. "Ahora yo me considero un practicante cristiano no por imposición como antes. Vivo la fe desde el lugar donde estoy y decido libremente lo que quiero seguir".

Este sector de creyentes evangélicos que transita entre los espacios no eclesiásticos con mucha más frecuencia que antes construye hoy nuevas formas de relacionamiento con los no creyentes evangélicos y construye su identidad tomando distancia de aquel perfil evangélico caracterizado por su desconexión del mundo y por su distanciamiento de las prácticas profanas. "Yo me considero una creyente distinta a lo que se espera en la iglesia, porque, por ejemplo, yo no paro poniendo en el Facebook todo el día 'Gloria a Dios, aleluya', relata Angela, una creyente de una congregación de clase media. "Yo no tengo ese vocabulario que caracteriza, digamos, a los cristianos evangélicos ino? No niego que soy cristiana y saben que hago música para Dios, pero yo siempre les trato de explicar que, en realidad no soy ninguna religiosa o una fanática, sino que tengo una relación mostra ${ }^{5}$ con el Señor", agrega.

Este peregrinaje de creyentes que buscan espacios religiosos menos dogmatizados y desverticalizados, dentro y fuera del campo evangélico, está generando cambios en algunas congregaciones cuyos líderes empiezan a ser más flexibles, especialmente con relación al cumplimiento de las normas y las prácticas de los rituales. De este modo, crean las condiciones para que los creyentes puedan reconectar su experiencia religiosa actual con aquellos referentes culturales que en su iniciación de fe o su etapa inicial de conversión tuvieron que anular o poner en paréntesis.

Aquí es importante observar que, si bien las normas establecidas por la institución religiosa constituyen un marco de referencia importante, los

${ }^{5}$ Esta es una expresión popular en Perú, que se refiere a persona, cosa o circunstancia que causa buena impresión o genera alta satisfacción. 
creyentes - con sus nuevas formas de vivir no solo su espiritualidad, sino también su propia pertenencia a la comunidad religiosa - se constituyen en legitimadores de aquellas prácticas o experiencias religiosas que se establecen en la vida cotidiana (Ammerman, 2007).

Asimismo, es importante observar que, a diferencia del pasado, muchos de los fieles que antes construían su mundo o su identidad desde el referente religioso, hoy construyen sus discursos y prácticas desde diferentes referentes, en donde lo religioso se constituye en uno de los marcos de referencia. Este perfil de creyente pone en cuestión el modelo de las identidades fijas y estables, y plantea dinámicas más abiertas de identificación y fidelización religiosa (De la Torre, 2013).

\section{Reflexiones finales}

Nuestros hallazgos pueden constituir un aporte al debate en torno al lugar y la incidencia de los evangélicos en el escenario religioso cada vez más pluralizado. Edward Cleary sostenía, en el 2004, que la población evangélica solamente representaría una minoría por sus extremas exigencias en término de disciplina de vida que nunca podrían ser cumplidas por todos los creyentes de las congregaciones adscritas a esta confesión (Cleary, 2004). Los evangélicos, sostenía Cleary, siguen aspirando a formar una sociedad de perfectos. Sin embargo, en este artículo, hemos mostrado como un vasto sector de creyentes evangélicos entran en discusión con las normas de su iglesia y desarrollan una determinada forma de autonomía.

Nuestro estudio nos hace pensar que un importante sector de los evangélicos está pasando de ser comunidades autoexcluidas de puros a una religión cada vez más plural y con una variedad y diferentes niveles de compromiso y fidelización con la comunidad a la que se adscriben. La experiencia que vive hoy este sector de los creyentes evangélicos ha empezado a generar, en varias congregaciones protestantes, un proceso de replanteamiento de las estrategias de acompañamiento y "pastoreo" de sus miembros, que se traduce no solo en la construcción de relaciones menos impositivas con sus fieles, sino también en la inclusión de los temas o problemas sociales en el discurso pastoral. 
En este contexto podemos observar diversos grados de autonomía y variados sentidos de pertenencia a la comunidad eclesial, pero esta variedad justamente es lo que permite que puedan operar en formas muy diversas en relación con los referentes y discursos religiosos "tradicionales" (Seman, 2013). De igual modo, observamos un entramado amplio desde el que lo sagrado interactúa con lo profano de manera fluida.

En ese sentido, los relatos de los creyentes evangélicos entrevistados nos permiten apreciar, por un lado, un campo evangélico marcado por diversas formas de habitar, transitar y pertenecer a la comunidad religiosa. Por otro lado, los casos nos revelan que la experiencia de lo sagrado en el contexto urbano de la Lima contemporánea confirma que la secularización en nuestro contexto ocurre sobre la base de una dinámica social en la que los usos populares de la religión producen constantemente nuevas síntesis entre lo ajeno y lo propio, lo tradicional y lo moderno; pero sobre todo, propician también la sacralización de los espacios seculares y la desacralización de ciertas prácticas religiosas (Parker, 2009).

Catalina Romero es PhD en Sociología, profesora del del Departamento Académico de Ciencias Sociales - Sección Sociología de la Pontificia Universidad Católica del Perú, Lima, Perú.

ఏjromero@pucp.edu.pe.

Rolando Pérez es Magíster en Periodismo, doctorando en Sociología (PUCP) y Profesor Asociado del Departamento Académico de Comunicaciones - Sección Comunicación de la Pontificia Universidad Católica del Perú, Lima, Perú.

” rperez@pucp.edu.pe.

Véronique Gauthier Lecaros es Doctora en Teología católica y Profesora del Departamento de Humanidades, de la Pontificia Universidad Católica del Perú, Lima, Perú.

ఏ rvgauthier@pucp.pe. 


\section{Referencias}

1. AMMERMAN, Nancy. Everyday religion: observing modern religion lives. New York: Oxford University Press, 2007.

2. AMMERMAN, Nancy. Response by Nancy Ammerman: modern altars in everyday life. In: BERGER, Peter. The many altars of modernity: toward a paradigm for religion in a pluralist age. Boston, Berlin: De Gruyter, 2014.

3. BERGER, Peter. The many altars of modernity: toward a paradigm for religion in a pluralist age. Berlin, Boston: De Gruyter, 2014.

4. CASANOVA, José. The secular and secularisms. Social Research, v. 76, n. 4, p. 1049-1066, 2009.

5. CLEARY, Edward. Shopping around: questions about Latin American conversions. International Bulletin of Missionary Research, v. 28, n. 2, p. 5054, 2004. https://doi.org/10.1177/239693930402800201

6. DILLON, Michelle. Postsecular Catholicism: relevance and renewal. New York: Oxford University Press, 2017.

7. DROOGERS, André. The cultural dimension of Pentecostalism. In: ROBECK, Cecil; YONG, Amos. The Cambridge companion to Pentecostalism. Cambridge University Press, 2014.

8. DE LA TORRE, Renée. Una agenda epistemológica para replantear las maneras de entender la secularización en América Latina. In: GIMÉNEZ, Verónica; GIUMBELLI, Emerson (Eds). Religión, cultura y política en las sociedades del siglo XXI. Buenos Aires: Editorial Biblos-ACSRM, 2013.

9. ESCOBAR, Samuel. Changing tides: Latin America and World Mission Today. New York: Orbis Books, 2002.

10. FONSECA, Juan. Conceptos básicos para comprender el mundo evangélico en el Perú. Revista Argumentos, v. 12, n. 1, p. 34-41, 2018.

11. FRESTON, Paul. History, current reality and prospects of Pentecostalism in Latin America. In: GARRARD-BURNETT, Virginia; FRESTON, Paul; DOVE, Stephen. The Cambridge history of religions in Latin America. Cambridge University Press, 2016, p. 430-450.

12. GOOREN, Henry. Religious conversion and disaffiliation: tracing patterns of change in faith practice. New York: Palgrave, Macmillan, 2010.

13. HERVIEU-LEGER, Danielle. El peregrino y el convertido. La religión en movimiento. México, D. F.: Ediciones del Helénico, 2004.

14. LALIVE-D'ÉPINAY, Christian. El refugio de las masas. Santiago de Chile: Editorial del Pacifico, 1968.

15. LECAROS, Véronique. La pratique dominicale au Pérou, essai de diagnostic.

Revue des Sciences Religieuses, v. 93, n.1-2, p. 137-159, 2019. 
16. LECAROS, Véronique. Estudios de recorridos religiosos: los desafiliados en contexto. Estudos de Religião, v. 31, n. 3, epub, 2017. http://dx.doi. org/10.15603/2176-1078/er.v31n3p71-90.

17. LEVINE, Daniel, Pluralism as challenge and opportunity. In: HAGOPIAN, Frances (Ed.), Religious pluralism, democracy, and the Catholic Church in Latin America. Notre Dame, Indiana: University of Notre Dame Press, 2009.

18. MALLIMACI, Fortunato. El mito de la Argentina laica: catolicismo, politica y Estado. Buenos Aires: Capital Intelectual, 2015.

19. MARZAL, Manuel. Categorías y números en la religión del Perú hoy. In: MARZAL, Manuel; ROMERO, Catalina; SÁNCHEZ, José (Eds.). La religión en el Perú al filo del milenio. Lima: Fondo Editorial PUCP, 2000. p. 21-58.

20. MILLER, Donald. Introduction, Pentecostalism as a global phenomenon. In: MILLER, Donald; SARGEANT, Kimon; FLORY, Richard. Spirit and power: the growth and global impact of Pentecostalism. Oxford University Press, 2013. p. 1-23.

21. MIGUEZ-BONINO, José. Rostros del protestantismo latinoamericano. Buenos Aires: Nueva Creación, 1995.

22. OUALALOU, Lamia. Jésus t'aime : la déferlante évangélique. Paris: Cerf, 2018.

23. PARKER, Cristian. Education and increasing religious pluralism in Latin America: the case of Chile. In: HAGOPIAN, Frances (Ed.) Religious pluralism, democracy and the Catholic Church in Latin America. Notre Dame, Indiana: University of Notre Dame, 2009. p. 131-182.

24. PÉREZ, Rolando. Las apropiaciones religiosas de lo público: el caso de los evangélicos en el Peru. In: ROMERO, Catalina (Ed.). Diversidad religiosa en el Perú: miradas múltiples. Lima: PUCP, 2016. p. 195-217.

25. PÉREZ-GUADALUPE, José Luis. Entre Dios y el Cesar: el impacto político de los evangélicos en el Perú y América Latina. Lima: Konrad Adenauer Stiftung, 2017.

26. PEW RESEARCH CENTER. Religión en América Latina. Cambio generali $\neg$ zado en una región históricamente católica, 13 nov. 2014. Disponible en: https:// www.pewresearch.org/wp-content/uploads/sites/7/2014/11/PEW-RESEARCHCENTER-Religion-in-Latin-America-Overview-SPANISH-TRANSLATION-forpublication-11-13.pdf

27. PICON, Raphaël; GAGNEBIN, Laurent. Le protestantisme: la foi insoumise. Paris: Flammarion, 2005.

28. RABBIA, Hugo H.; MORELLO, Gustavo.; DA COSTA, Néstor; ROMERO, Catalina (Eds.). La religión como experiencia cotidiana: creencias, prácticas y narrativas espirituales en Sudamérica. Córdoba, Lima, Montevideo: EDUCC, Fondo Editorial PUCP, UCU, 2019. 
29. SANCHEZ, José. Cambios y modernización en el pentecostalismo popular peruano: el Centro Apostólico Misionero Ríos de Agua Viva de San Juan de Lurigancho. In: ROMERO, Catalina (Ed.). Diversidad religiosa en el Perú: miradas múltiples. Lima: PUCP, 2016. p. 156-167.

30. SEMAN, Pablo. Las industrias culturales y la transformación del campo religioso: procesos y conceptos. In: ALGRANTI, Joaquín; SEMAN, Pablo (Eds.). La industria del creer: sociología de las mercancías religiosas. Buenos Aires: Editorial Biblos, 2013. p. 19-35.

Recibido: 27 sept. 2019.

Aceptado: 4 ene. 2020. 